\title{
Fit Among Business Strategy, Strategy Formality, and Dynamic Capability Development in New Product Development
}

\author{
Lale Gumusluoglu ${ }^{1}$ and Nuran Acur ${ }^{2,3}$ \\ ${ }^{1}$ Faculty of Business Administration, Bilkent University, Ankara, Turkey \\ ${ }^{2}$ Faculty of Business, Ozyegin University, Istanbul, \\ ${ }^{3}$ Turkey and University of Strathclyde, Glasgow, UK
}

\begin{abstract}
Taking new product development (NPD) as the unit of analysis, this study, based on strategic fit approach, investigates the effects of NPD strategy formality and dynamic capabilities (sensing, seizing, and reconfiguring) on NPD performance for different business strategy types (prospectors, analyzers, defenders). The sample of the study includes 203 companies from nine countries: Australia, Denmark, Finland, Norway, the Netherlands, Slovakia, Portugal, Spain, and Turkey. The study finds that a formal NPD strategy is an important driver of NPD performance for all companies regardless of the strategy pursued. Of the dynamic capabilities, sensing capabilities have significant performance effects for all strategy types. Seizing capabilities have stronger effect on NPD performance for prospectors and analyzers, than for defenders while reconfiguring capabilities is a driver of performance only for defenders. Furthermore, dynamic capabilities explain NPD performance above and beyond strategizing, irrespective of the strategy pursued.
\end{abstract}

Keywords: NPD strategy formality; dynamic capabilities; business strategy; NPD performance

\section{Introduction}

With the growing level of competition across industries, dynamic capability development in new product development (NPD) has been at the heart of product competition for more than a decade (e.g., Brown and Eisenhardt, 1995; Deeds et al., 1999; Marsh and Stock, 2003; Prieto et al., 2009). Dynamic capabilities consist of 'specific strategic and organizational processes that create value for firms within dynamic markets by manipulating resources into new value-creating strategies' (Eisenhardt and Martin, 2000: 1106). Dynamic capability literature claims that a firm's competitive advantage is informed by its business strategy that exploits its assets, resources and competences in a systematic way (O'Connor, 2008). Accordingly, dynamic capabilities are about a firm's ability to acquire, integrate, and adapt its skills and resources to the rapidly changing environment (Teece et al., 1997; Teece, 2007; Wu, 2007; Easterby-Smith and Prieto, 2008). Firms differ considerably in their efforts to develop business

Correspondence: Lale Gumusluoglu, Faculty of Business Administration, Bilkent University, 06800 Bilkent Ankara Turkey. Tel: 90-312-2902319; Fax: 90-312-2664958; E-mail: tomruk@bilkent.edu.tr strategies and dynamic capabilities in product competition, which can yield a range of diverse performance affects (e.g., Day, 1994; Eisenhardt and Martin, 2000). Yet despite the theoretical and managerial importance of this issue, researchers know little about how different capabilities should be organized for NPD in firms with different business strategies. Furthermore, the ability to generate new products is also suggested to be dependent on a clearly defined strategy (i.e., NPD strategy formality) (Cooper et al., 2004). In this vein, our research question is: How can NPD strategy formality and dynamic capabilities lead to superior NPD performance for firms with different business strategies?

Examining this complicated theoretical and managerial problem raises two significant challenges. First, the development of dynamic capabilities and business strategies are each viewed as multidimensional phenomena involving many different but related issues. Yet strategy scholars frame the relationships between these phenomena in holistic terms as the role of dynamic capabilities in implementing business strategy. Put differently, how well a firm implements a business strategy is influenced by how well it adapts its products, processes, and organizational routines (i.e., dynamic capabilities) to the requirements of its environment. Teece 
et al. (1997) suggest that, in dynamic environments, firms should not only have strong resources (resourcebased view; RBV), they must also have strong organizational routines for developing and renewing those resources and organizational capabilities, specifically, sensing, seizing, and reconfiguring capabilities. While all companies have to develop these three components of dynamic capabilities to adapt to the rapidly changing environment, the ability to do so 'is not uniformly distributed amongst enterprises' (Teece, 2007: 1323). Accordingly, the extent to which firms might develop each of these capabilities is dependent on many factors such as their strategies, structures, established capabilities, complementary assets, and administrative routines. For example, leader companies might invest heavily in identifying market opportunities to maintain their leadership positions, while others might emphasize reconfiguring their existing competences to address the needs of their current customers.

Successfully organizing dynamic capabilities for different business strategies involves resolving multiple and conflicting strategic possibilities to match environmental changes. Scholars suggest that various dimensions of dynamic capabilities can be assessed in terms of their 'fitness' (Matsuno and Mentzer, 2000; Augier and Teece, 2007; Teece, 2007). Accordingly, the business strategy pursued by a firm influences the relative emphasis it might put on capability development (McKee et al., 1989; Zhou and Li, 2010). The alignment of dynamic capabilities with a firm's strategy and environment is the basis of this contingency approach to strategy (McKee et al., 1989; Di Benedetto and Song, 2003; Song et al., 2007; Zhou and Li, 2010). Although strategic management scholars state that a firm has competitive advantage in NPD when its dynamic capabilities fit its business strategy (Di Benedetto and Song, 2003; Harreld et al., 2007), the wide range of possible levels of fitness makes the identification of 'correct' configurations of dynamic capabilities needed for a particular business strategy difficult and complex. Therefore, the first challenge that strategy and NPD scholars face lies in assessing how the different components of dynamic capabilities can be organized to enable the implementation of particular business strategies in product competition. Hence, we suggest that for different business strategies, different components of dynamic capabilities (i.e., sensing, seizing, and reconfiguring) are more important for their effects on NPD performance.

In a similar vein, we suggest that the extent to which firms formalize their NPD strategies is dependent on their business strategy. Although several studies suggest that firms need clearly defined strategies on which to focus their efforts and allocate resources, and a plan for carrying out their goals (Cooper et al., 2004), previous research yielded inconsistent findings about the strategy formality-performance link. Hence, we introduce business strategy as a contingency factor in this link and suggest that the extent to which NPD strategy formality influences NPD performance is dependent on business strategy.

The second problem area in the strategy domain relates with whether competitive advantage stems from investing in dynamic capability development, rather than in strategy formalization. Hence, scholars point out that dynamic capabilities can affect performance above and beyond strategizing. While in general strategies are outward-looking, since they are a result of managerial responses to external environmental conditions (Fiegenbaum and Thomas, 2004; Veliyath and Shortell, 1993), dynamic capabilities are inwardlooking and focus on how to integrate and rejuvenate a firm's resources (Zhou and Li, 2010). Accordingly, Teece et al. (1997: 509) state that '[i]dentifying new opportunities and organizing effectively and efficiently to embrace them are generally more fundamental to private wealth creation than is strategizing.' Based on these observations, this study aims to co-examine the effects of dynamic capabilities and NPD strategy formality on NPD performance.

The purpose of this paper, therefore, is to investigate how business strategy, NPD strategy formality and dynamic capabilities engage, if at all, to affect NPD performance. To this end, we explore the impact of NPD strategy formality and dynamic capabilities on NPD success. As noted previously, we focus on the three core components of dynamic capability (e.g., sensing, seizing, and reconfiguring capabilities) to examine this relationship because the extent to which firms focus on these components depends on their business strategy (Teece, 2007). We examine each component for their relationships to different business strategies based on the Miles and Snow (1978) typology (prospectors, analyzers and defenders) and examine their individual influences on NPD performance. Here, Miles and Snow's (1978) typology provides a way to conceptualize the major decisions that companies must make when they seek to fit their strategy formalization and dynamic capability development activities with their business strategies. In summary, we present a framework that synthesizes the knowledge in strategy formalization and dynamic capability development in the context of NPD and business strategy literature to understand their links to NPD performance. We also take environmental characteristics into account to identify the contingencies for our study.

Our study makes four contributions. First, we fill a major knowledge gap by providing empirical support for theorized links between dynamic capability, business strategy, and NPD performance. This helps managers understand how to organize and develop dynamic capabilities to meet the implementation requirements of different business strategies and why this is important in driving NPD performance. Second, our study examines 
the effects of NPD strategy formality on NPD performance for prospectors, analyzers, and defenders. While several studies show that the existence of a formal strategy is important for company performance (e.g., Brews and Hunt, 1999; Acur et al., 2012), we do not know how it impacts NPD performance for firms pursuing different business strategies. Third, despite accumulating research on the topic, few studies explore dynamic capabilities in an NPD context (e.g., Deeds et al., 1999; Marsh and Stock, 2003; Prieto et al., 2009). Examining dynamic capabilities in NPD is equally noteworthy because they enable adaptation to the environmental requirements which in turn foster NPD performance. Fourth, from a theoretical standpoint, by co-examining the performance effects of NPD strategy formalization and dynamic capability development, the study provides insights about whether dynamic capabilities can affect performance above and beyond strategizing in an NPD context. Such knowledge may be especially important for management resource allocation decisions.

\section{Theoretical background}

Firms differ considerably in their efforts in developing strategies and dynamic capabilities in product competition, which may cause different performance affects (e.g., Day, 1994; Eisenhardt and Martin, 2000). Studies rooted in strategic fit approach indicate that a firm's business strategy influences the relative emphasis it puts on capability development; in other words, dynamic capabilities should be organized in ways that enable implementation of a particular business strategy (McKee et al., 1989; Di Benedetto and Song, 2003; Song et al., 2007; Teece et al., 1997; Zhou and Li, 2010). Based on the strategic fit approach, which is generally accepted as necessary for business success (Augier and Teece, 2007; Matsuno and Mentzer, 2000; Teece, 2007), the study offers a model in an NPD setting and tests it for Miles and Snow's (1978) business strategy typology. Hence, in Figure 1, we combine insights from the strategy formalization, dynamic capabilities, and NPD literatures to

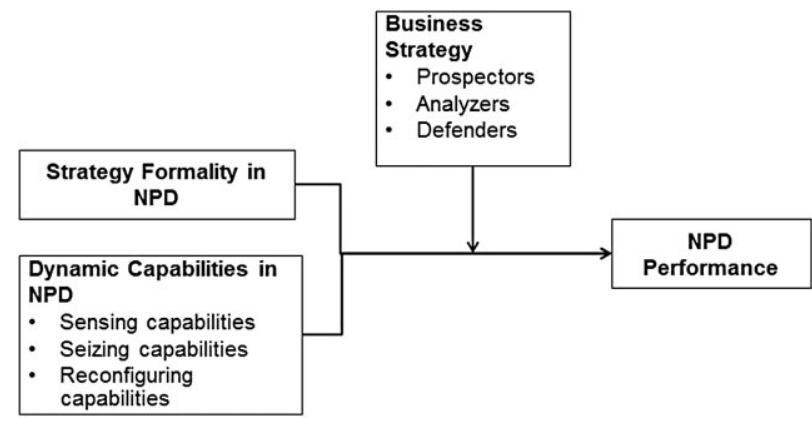

Figure 1. The proposed model develop a conceptual model that examines the relationships between NPD strategy formality, dynamic capabilities in NPD, and NPD performance for different types of business strategies. We specifically examine (1) the effects of NPD strategy formality and dynamic capabilities (sensing, seizing, and reconfiguring) on performance by taking the NPD function as the unit of analysis and (2) how the above relationships will vary for prospectors, analyzers, and defenders. Four factors (environmental hostility, and dynamism, firm size, and age) are used as control variables.

\section{Business strategy}

Because the present study focuses on NPD, we use Miles and Snow's (1978) typology, which focuses on intended rate of product-market change as compared to Porter's (1980) typology which focuses on customers and competitors (Hambrick, 2003). Previous research widely embraced Miles and Snow's (1978) typology and attributed the typology's excellence to its innate parsimony, industry-independent nature and to its correspondence with the actual strategic postures of firms across multiple industries and countries (Hambrick, 2003). Notably, in line with many previous studies which used Miles and Snow's typology (e.g., Shoham et al., 2002), the study's hypotheses do not include reactors, the fourth type of business strategy. As also suggested by Miles et al. (1978), because reactors do not have a consistent strategy-structure relationship and are not able to respond to their environmental changes effectively, this strategy type is not sustainable.

According to Miles et al. (1978), strategy is the pattern of decisions by which a company aligns itself with its environment. This 'adaptive cycle' comprises three stages: managing products and markets (the entrepreneurial problem); designing a system for producing and distributing products (the engineering problem); and developing organizational structures and processes to support the entrepreneurial and engineering decisions (the administrative problem). The three problems essentially concern a firm's positioning in the environment, its technology, and organizational design, respectively. Miles and Snow's (1978) strategic business types have their own way of solving the above problems. Several studies (e.g., Hambrick, 1983; Shoham et al., 2002) show that these strategy types differ in their performance objectives. Prospectors move quickly to take advantage of opportunities in the marketplace through new products, new markets, and new technologies. Defenders have a stable set of products and customers, and aggressively maintain their domain. Analyzers are a hybrid of prospectors and defenders; they focus on imitating the leaders (prospectors) in their industry, learn from the leaders' experiences, and develop improved products quicker and/or more efficiently. Analyzers are not first 
movers, but explore developments in line with market opportunities and product policies, prepare an adaptive mechanism for turbulent markets, and pursue efficiency in the stable markets they serve. Notably, firms pursuing different strategies may operate in the same industry; for example, in a rapidly changing market, prospectors may rely on leadership in NPD while defenders may seek to reduce risk exposure by heavily defending their positions (Desarbo et al., 2005).

\section{NPD strategy formality and business strategy}

A formal NPD strategy involves clear product concept statements, target markets, and a systematic project portfolio management (Cooper and Kleinschmidt, 1995). In other words, a firm's NPD strategy describes what the firm desires to achieve from its new products and provides strategic direction for its NPD activities (Brews and Hunt, 1999) by planning the role and goals of and allocating adequate resources to that function (Brown and Eisenhardt, 1995). This paper, then, defines NPD strategy formality as the degree to which a firm identifies a formal NPD strategy that clearly defines NPD goals, strategic arenas, or areas of focus, and the degree to which that strategy includes a formal portfolio management system to select projects and allocate development resources to them.

Scholars acknowledge the importance of having a clear, well-defined NPD strategy formality backed up by detailed action plans to new product success (e.g., Brown and Eisenhardt, 1995; Cooper and Kleinschmidt, 1995; Calantone et al., 2003; Acur et al., 2012). Cooper et al. (2004) identify a strong formal NPD strategy as a best practice. However, previous research yielded inconsistent findings about performance - strategy formality link. For example, Mintzberg (1990) asserts that the pre-determined and inflexible paths introduced by formal strategies create resistance to change. Conversely, Acur et al. (2012) claim that a formal NPD strategy can improve communication, increase integration, and reduce potential conflicts between NPD and marketing. Several studies show that formal strategies have positive influences on firm performance in unstable or dynamic environments (e.g., Priem et al., 1995), while others find that they are best suited to stable environments (e.g., Fredrickson and Mitchell, 1984). Based on an analysis of 656 firms, Brews and Hunt (1999) suggest that in unstable environments, firms should have specific but flexible plans and must be prepared to rework and change plans incrementally as implementation proceeds. That is, strategies are not always intended, but may emerge as organizations learn about their taskenvironments. From the above observations, this paper introduces business strategy as a contingency factor and argues that the performance effects of strategy formality will vary according to a firm's business strategy.
Miles et al. (1978) claim that prospectors conduct broad rather than intensive planning in their organic structures, characterized by low degrees of formalization and high degrees of decentralization. In a similar vein, Mintzberg et al. (1998) argue that prospectors should have clear vision and mission statements but flexible strategies so they can respond first to environmental changes. Supporting these conventions, Veliyath and Shortell (1993) and Slater et al. (2006) show that prospectors' performance is harmed by high levels of strategy formalization. While these studies examined the effects of strategy formality on the company-level performance of prospectors, we expect similar performance effects of NPD strategy formality at the NPD-level as well. Prospectors aim to be the market leader by finding and developing new products or technologies. These firms avoid long-term commitments to a single type of a product or technology; rather, they create multiple, prototypical offerings (Miles and Snow, 1978). Hence, a formally stated NPD strategy may bring rigidity into prospectors' entrepreneurial behavior. Entrepreneurs not only adapt but also shape their environments (Teece, 2007). Through introducing brand new products and technologies, prospector companies shape opportunities in the market. In constantly searching for opportunities, these companies may rely less on formal NPD strategies and more on emergent strategies that give them the flexibility to not only exploit the existing opportunities but also develop new ones and enhance their NPD performance. Hence, we propose that the presence of a formal NPD strategy will have weaker effects on the NPD success of the companies pursuing a leader strategy as compared to those with other than leader strategies.

Shortell and Zajac (1990) report that analyzers score significantly higher on strategy formalization. These companies cautiously follow prospectors into new product-market domains and seek efficiency in their more-stable markets. To deploy their resources effectively among this dual set of intentions and achieve equilibrium between the conflicting demands for flexibility and stability, these firms are expected to set priorities for their markets and formalize their strategies accordingly. Miles and Snow (1978) suggest that analyzers use some form of matrix structure where function managers unite with product managers to form a balanced coalition. Consequently, intensive planning between the functional areas concerning the stable domain and comprehensive planning among the functional and product divisions concerning new products and markets may be more appropriate for these companies. In these companies, a formal NPD strategy may ensure that NPD efforts receive sufficient resources and can help reduce conflict among stakeholders within the firm (Parry et al., 2009).

Defenders maintain a relatively stable domain by producing goods or services as efficiently as possible. These 
firms have centralized and mechanistic organizations where coordination is achieved through formal rules and procedures. To ensure efficiency, defenders rely on intensive cost-oriented planning (Miles et al., 1978). Veliyath and Shortell (1993) and Mintzberg et al. (1998) suggest that tightly coupled and centrally controlled firms tend to set more formalized, deliberate, and agreed-upon strategies and goals. Indeed, Slater et al. (2006) report that formal strategies have positive relationships with performance in defender companies. More importantly, the authors show that this process has the greatest effect on performance among defenders seeking low costs than among other business types. A formal NPD strategy and set of goals may enable defenders follow a clearly articulated sequence of steps in NPD which will in turn increase efficiency and also decrease operational uncertainty in this unit. From the above observations, we hypothesize that a formal NPD strategy will be a stronger driver for NPD performance for defenders and analyzers, than for prospectors.

Hypothesis 1. A formal NPD strategy will have a stronger positive effect on NPD performance for analyzers and defenders, than for prospectors.

\section{Dynamic capabilities in NPD}

Capabilities are 'complex bundles of skills and accumulated knowledge, exercised through organizational processes that enable firms to coordinate activities and make use of their assets' (Day, 1994: 38). Accordingly, dynamic capabilities concern a firm's ability to acquire, integrate, and adapt its skills and resources to a rapidly changing environment (Teece et al., 1997; Teece, 2007; Wu, 2007; Easterby-Smith and Prieto, 2008). These abilities are rooted in a firm's organizational and knowledge processes, through which resources are obtained, combined, and deployed (Zollo and Winter, 2002) and enable the firm to achieve greater innovation and better organizational performance (Kyrgidou and Spyropoulou, 2012). For this reason, NPD is proposed as an ideal frame for development of dynamic capabilities (Eisenhardt and Martin, 2000; Prieto et al., 2009). To clarify the concept of dynamic capabilities, the current literature differentiates between operational (zero-order) and dynamic (firstorder) capabilities (Zollo and Winter, 2002; Winter, 2003). The former include activities related to a firm's operational functioning, while the latter facilitate sensing new opportunities, creating new asset combinations, and building new capabilities to match new market needs (Cepeda and Vera, 2007; Zahra et al., 2006). Building on these perspectives, this paper cites dynamic capabilities as a firm's higher-order capabilities (sensing, seizing, and reconfiguring), which bring about new combinations of resources and operational routines to address environmental changes. While many factors affect a firm's ability to develop dynamic capabilities, this paper's theoretical discussion is rooted in Teece's (2007) three components of dynamic capability development: (1) sensing capabilities; (2) seizing capabilities; and (3) reconfiguring capabilities.

Sensing capabilities (identifying and integrating opportunities) require firms to continuously scan, search, and explore markets and technologies (Teece, 2007). Sensing new opportunities not only involves investment in in-house $R \& D$, it also involves external search which embraces potential collaborators such as customers, suppliers and universities. In an NPD context, building sensing capabilities requires firms to identify and exploit internal and external sources of new product/process ideas (e.g., suppliers, competitors, customers) as well as to integrate existing knowledge with external knowledge (e.g., interpreting and internalizing past NPD projects, as per Marsh and Stock, 2003). Seizing capabilities (building competences) 'involves maintaining and improving technological competences and complementary assets and then, when the opportunity is ripe, investing heavily in the particular technologies and designs most likely to achieve marketplace acceptance' (Teece, 2007: 1326). Competence is 'an ability to accomplish something by using a set of material (e.g., equipment, machinery, mailing lists) and immaterial resources (e.g., manufacturing know-how, an understanding of customer needs)' (Danneels, 2002: 1102). As such, seizing capabilities comprise building and improving competences and deploying (e.g., learning capabilities) resources from internal and external sources. Reconfiguring capabilities (reconfiguring competences) is 'the firm's ability to sense the need to reconfigure its asset structure and to accomplish the necessary internal and external transformation' (Teece et al., 1997: 520). In an NPD context, reconfiguration concerns a firm's ability to change the patterns of previously utilized processes to enhance the development of existing products or its ability to develop new products (Zollo and Winter, 2002; Cepeda and Vera, 2007). Hence, reconfiguration might take the form of adjusting existing NPD processes to future time, cost, and process requirements. While reconfiguring, companies can also leverage their complementary assets and capabilities to dynamically revive themselves, such as in the case of Nintendo, who relied on its software-driven mindset to produce novelty in its hardware development process (Subramanian et al., 2011).

\section{Sensing capabilities and business strategy}

Because competitive advantage is often short-lived in dynamic markets, continually searching for opportunities is a critical dynamic capability for firms in such markets, who often compete by creating a series of temporary advantages rather than by building a long-term position in 
a specific product or technology. Hence, 'their strategic logic is opportunity' (Eisenhardt and Martin, 2000: 1117); they achieve strategic advantage by identifying opportunities and integrating them into their internal activities and technologies. Opportunities may also reside in their existing knowledge base and experiences.

Prospectors are technologically innovative, ready to pursue and accept state-of-the-art technologies, consistently first in adopting new ideas, and show greater risktaking behavior than defenders and analyzers (Miles and Snow, 1978; Hambrick, 1983; Shortell and Zajac, 1990). These firms owing to their decentralized organizations with great local autonomy are more likely to spot market and technological opportunities (Teece et al., 1997). Because prospectors deal with time-based competition and aim to produce products of great variety with stateof-the-art technologies and design very quickly, they have a high level of entrepreneurial orientation; continually hunting for external and internal opportunities (i.e., technological, design, market, and product opportunities) ahead of their competitors and exploiting them to maintain their reputations as innovators. Such continuous monitoring of the external environment enables such firms to not only spot opportunities that will better suit the needs of the markets but also helps them avoid overreliance on past practices (Kyrgidou and Spyropoulou, 2012). Teece (2007) notes that good entrepreneurial management is needed to sense and seize opportunities. This attribute stems not only from prospectors' domain knowledge but also from their high proactivity and integration skills. These firms use an open-minded inquiry process, where they actively and systematically scan the environment for changes and unexploited opportunities (Day, 1994). Hence, prospectors continuously (re)create their own markets by rapid product innovations. For instance, $3 \mathrm{M}$ incorporates solutions to unarticulated customer needs for new products by working closely with lead users (customers who recognize a need before the majority of the market).

Defenders have a narrow product-market domain and therefore often ignore developments outside of it (Miles et al., 1978). These firms, also due to their centralized organizations are more likely to be blindsided by market and technological opportunities (Teece et al., 1997). They mostly focus on producing and distributing their goods/services as efficiently as possible, investing a great deal of resources in solving problems, for example, by process reengineering (Miles et al., 1978). Defenders are thus expected to emphasize reconfiguring capabilities more than sensing and seizing capabilities. Analyzers share characteristics with prospectors and defenders. They aim to integrate products developed by prospectors. As they try to more cheaply produce the best products developed by the prospectors, they are expected to put less emphasis on scanning technological or market trends but instead have a close eye on the products of prospectors which have a proven success in the market. Based on the above observations, this paper expects that of the three strategic types studied, sensing capabilities would be most important to prospectors for enhancing their NPD performance as compared to analyzers and defenders.

Hypothesis 2. Sensing capabilities will have a stronger positive effect on NPD performance for prospectors, than for analyzers and defenders.

\section{Seizing capabilities and business strategy}

Competences can be enhanced through developing new ideas or exploring new technological developments by tapping into internal (e.g., manufacturing department, marketing department.) or external sources (e.g., collaborations, partnerships). Acquiring such resources is a necessary but not sufficient condition for firm success; learning across individuals, groups, and organizational boundaries must also occur for such competences to become dynamic capabilities (Cepeda and Vera, 2007; Easterby-Smith and Prieto, 2008). That is, knowledge must be transferred throughout the organization, integrated with other knowledge areas, and applied to a new product or process because solutions to NPD problems may reside in different functional or organizational units (Schulze and Brojerdi, 2012; Kessler et al., 2000). Through absorptive capacity - 'the ability of a firm to evaluate and assimilate external knowledge' (Cohen and Levinthal, 1990: 128) - firms absorb and integrate new knowledge into their domains, which over time enhances their dynamic capabilities, and in turn their NPD capabilities (Deeds et al., 1999). Creating a shared understanding of internal and external knowledge through market communication systems, technology assessments and benchmarking in the organization fosters the new knowledge creation needed for NPD (Dougherty et al., 2000).

Prospectors would not only be expected to sense opportunities in the market but also to build relevant competences to address those opportunities (Conant et al., 1990). To maintain their leadership positions, it is equally important for these firms to build and deploy distinctive resources faster than others. Indeed, innovative firms have been shown to possess significantly higher resource allocation and learning capabilities than conservative firms (Yam et al., 2004). It is especially critical for prospector firms to build a learning organization and culture supportive of innovation. Siguaw et al. (2006: 563) state that '[a]n innovation-oriented firm encourages and facilitates knowledge transfer across and within subunits to retain diversity of views and fosters cooperative beliefs and understandings among all functional areas to direct them toward innovation.' Song et al. (2008) report that prospectors have 
greater IT capabilities than analyzers and defenders, which allow them to facilitate the intra-organizational communication flow and cross-functional integration needed for learning capabilities.

Analyzers try to improve their technological competences and complementary assets while retaining a base of traditional segments and competences. Hence, similar to prospectors, these firms need to build competences to respond to new customer preferences and similar to defenders, they need to reconfigure their existing competences to better address the needs of current customers. These firms are thus likely to develop learning systems that facilitate distributing and sharing new information across functional boundaries. Defenders, with their emphasis on operational efficiency and protecting their mature market positions, are generally less focused on building new competences as compared to prospectors and analyzers. Even if these companies sense a business opportunity, they may be less willing to seize it due to their bureaucratic and administrative routines which reinforce risk aversion and status quo orientation. Furthermore, their mechanistic organizations and slow decision-making processes (Miles et al., 1978) may become obstacles in seizing opportunities in the NPD unit since seizing capabilities can be used effectively if data is collected and disseminated throughout the organization in a timely manner. Hence, we argue that, unlike prospectors and analyzers, seizing capabilities will be less important for the NPD performance for these companies.

Hypothesis 3. Seizing capabilities will have a stronger positive effect on NPD performance for prospectors and analyzers, than for defenders.

\section{Reconfiguring capabilities and business strategy}

Reconfiguring capabilities refers to a firm's ability to enhance, combine, protect, and adjust its intangible and tangible assets (Teece, 2007). Those capabilities include modifying existing systems and aligning the organization with its technologies, processes, strategy, and environment. Contingency theories hypothesize that such consistency is required for a company to be most effective (e.g., Mintzberg, 1990). Similarly, Koufteros et al. (2002) suggest that companies need to fit their product development function to the industry to enhance their competitiveness.

Defenders mainly focus on better penetrating markets and improving their products (Dvir et al., 1993). These firms offer a limited range of products and protect their niche by offering lower prices or higher quality and better service than their competitors. Defenders must determine how to achieve strict control of the organization to ensure efficiency, hence, their strategy is characterised by tight cost control (e.g., adjusting NPD processes to future cost requirements). Therefore, it is really important for these companies to enhance their adaptive capabilities and decrease their costs. In other words, reconfiguring capabilities is a major driver for them in enhancing their NPD performance.

Analyzers, who follow a hybrid strategy, face conflicting goals of flexibility and efficiency. To respond to changing customer preferences, they not only need to invest in the necessary resources to develop appropriate new products, but also refine their production processes to match those new needs (Poulis and Jackson, 2010; Zhou and $\mathrm{Li}, 2010$ ), that is, build and reconfigure competences to improve performance. For example, these firms rapidly adapt new product designs to fit their existing stable technologies (Miles et al., 1978). Prospectors' interests lie in actively exploiting new product/ technology opportunities in order to bring about brand new products with the latest designs and technologies (Walker and Ruekert, 1987). Although these companies also reconfigure their systems / production technologies and processes (e.g., reprogramming the robots, new tooling, reeducating their employees, etc.) to address existing demands to some extent, given their ambition for the brandnew products and technologies, they will benefit the least from reconfiguring capabilities for the development and performance of their new products in the market.

Hypothesis 4. Reconfiguring capabilities will have a stronger positive effect on NPD performance for defenders and analyzers, than for prospectors.

\section{Research methodology}

\section{Research design}

The data in this study were drawn from the international 'Patterns in NPD' survey, which was designed to collect information about NPD practices and performance. In the present study, data collected from nine countries is used: Denmark, Australia, Finland, Norway, the Netherlands, Slovakia, Portugal, Spain, and Turkey. The sampling frame consisted of 4,527 randomly selected firms from all nonservice firms listed in the European databases EPO, Nnerhverv, Voitto, FME, Chamber of Commerce, Diagnose and DUNS. A pre-survey telephone inquiry was made to all 4,410 firms to verify the suitability of the company in terms of number of full-timeequivalent (FTE) product development employees in the NPD function and for requesting preapproval of participation. The study's sampling frame consists of 1,597 suitable companies which were independent firms and strategic business units of large firms with at least five or more FTE product development employees. Of these 1,597, companies, 445 firms agreed to participate and 
provided a contact person. The surveys were administered separately by research coordinators in each of the countries, and data were pooled in a common database. For Portugal, Turkey, Spain, and Slovakia the questionnaire was translated by native speakers, and translated back by other native speakers. For the other countries, an English version of the questionnaire was used.

In administering the final survey, the total design method for survey research was followed (Dillman, 2000). The first mailing package included a personalized letter, the survey, and a priority postage-paid envelope with an individually typed return address label. The survey was sent to 445 firms that agreed to participate. The contact person was asked to distribute the survey to the NPD or R\&D manager of the company who has been involved in developing new products or has knowledge of new product programs in his/her organization.

To increase the response rate, four follow-up mailings to the companies were sent. One week after the mailing, a follow-up letter was sent. Two weeks after the first follow-up, a second package with same content as the first package was sent to all nonresponding companies. After two additional follow-up letters, questionnaires were collected from 203 companies, representing a response rate of $45 \%(203 / 445)$.

\section{Measures}

Multi-item scales were developed based on the literature on NPD and strategic management. When existing scales were unavailable, new scales and measures were developed. To develop reflective scales, the framework proposed by Churchill (1979) was used. Constructs were defined, an item pool was generated, and the measurement format was decided on. A list of potentially useful measures was developed from the literature. The initial item tool was reviewed by a number of experts in academia and industry. On the basis of this review, some statements were dropped, and a few were modified.

Items adapted from Cooper and Kleinschmidt's (1995) and Cooper et al.'s (2004) best-practices scales measure NPD strategy formality. Respondents indicated their level of agreement with each statement on a scale from 1 ('strongly disagree') to 7 ('strongly agree'). Sample items included: 'There is a formally stated NPD strategy,' 'We have clearly defined goals for all our individual new products,' and 'The project portfolios are aligned with the business strategy.' This construct is validated by Kandemir and Acur (2012), who used the same database $(\mathrm{AVE}=58.9 \%$; $\mathrm{HSV}=22 \% ; \mathrm{CR}=0.80)$.

Regarding dynamic capabilities, respondents indicated the extent to which their NPD unit achieves objectives of identifying opportunities, building competences, and reconfiguring competences on a scale of 1 ('not at all achieved') to 7 ('very well achieved'). Six items measured sensing capabilities, of which two concerned new product-market options (adapted from Johnson et al., 2003), three concerned windows of opportunity (from De Brentani and Kleinschmidt, 2004), and one concerned proactive market orientation (from Narver et al., 2004). Sample items included: 'Our current development projects include new product-market options,' 'NPD is successful in opening new markets to our organization,' and 'We incorporate solutions to unarticulated customer needs in our new products.' Using the same database, Kandemir and Acur (2012) validated the measure of sensing capabilities, which they labeled as 'windows of opportunity' ( $\mathrm{AVE}=49.8 \%$; $\mathrm{HSV}=26 \%$; $\mathrm{CR}=0.80$ ).

Seizing capabilities is measured by six items, four of which concerned the ability to acquire resources (ideas and technologies) from internal and external sources (adapted from Kessler et al., 2000) and two the ability to deploy resources (Yam et al., 2004). Sample items included: 'We built upon manufacturing competences for the exploitation of new technological developments' and 'We can pass lessons learned across organizational boundaries.' Using the same database, Acur et al. (2010) validated this measure, which they labeled as 'competence development' $\quad(\mathrm{AVE}=67.2 \% ; \mathrm{HSV}=33.0 \%$; $\mathrm{CR}=0.90$ ).

Reconfiguring capabilities is measured by six items, one of which concerned anticipating total time (Griffin, 1997), two of which concerned firms' ability to adjust the speed (Griffin and Page, 1993), and three the ability to adjust the productivity and flexibility of NPD processes to future requirements (Clark and Wheelwright, 1993; Thomke, 1997). Sample items included: 'We are able to adjust our NPD process to future time requirements,' 'We are able to adjust our development process to future cost requirements,' and 'We are able to adjust the average time of product redesign to future requirements'.

A six-item scale measured NPD performance, concerning four items (customer satisfaction, timeliness, cost, and quality of new products) adapted from Chiesa et al. (1996) and two items (sales/returns from new products) from De Brentani and Kleinschmidt (2004). This measure reflects product concept effectiveness in terms of 'fits with market demands' or 'market acceptance of the new product' (see the meta review about product development by Brown and Eisenhardt, 1995) as well as the financial performance of the new product. Sample items included: 'Our new products meet customer requirements,' 'The impact of our NPD program on our sales level is positive,' and 'We get good returns from our NPD program relative to our spending on it.' The seven-point scale for the capabilities measure was also used for this performance measure.

To determine the business strategy companies pursued, respondents read four texts each describing a strategy type (from Snow and Hrebiniak's 1980 definitions), and via a self-typed paragraph identified the 
strategy that most closely described their business unit's approach. Many studies validate this measurement method (e.g., Conant et al., 1990; Shortell and Zajac, 1990). Based on the responses, the sample included 80 prospectors, 97 analyzers, 26 defenders, and six reactors. Because the study is not interested in reactors, those six companies were removed from further analysis. Respondents next identified the portion of innovative products in their total sales, determining the percentages of annual sales of four types of products: breakthrough new products, next-generation new products, additions to the product family and/or derivatives/enhancements, and non-modified products introduced in the last three years. This question functioned as a proxy for the type of strategy and was used to verify the answers subjectively provided by the respondents.

Based on the responses, the authors defined prospectors as respondents whose sales portfolio consists of more than $60 \%$ breakthrough innovations and nextgeneration new products (i.e., a high sales percentage of radical innovations). Defenders' sales portfolios consist of more than $60 \%$ non-modified products and additions to the product family and/or derivatives/enhancements (i.e., a high sales percentage of existing products). Analyzers' sales from breakthrough innovations and next generation new products range between $40 \%$ and $60 \%$ (Laugen et al., 2006). If inconsistency between two classification criteria occurred, the percentage distribution of the company's total NPD activities accounted for by each of the four product categories (included in the questionnaire) functioned as an additional criterion. Accordingly, the authors labeled 58 companies as prospectors, 119 as analyzers, and 26 as defenders for analysis purposes.

The market environment directly impacts new product performance and the strategy-performance relationship (McKee et al., 1989; Gatignon and Xuereb, 1997). Accordingly, this study controls for environmental hostility and dynamism, measuring two items for the former and three items for the latter (Bantel, 1998). Sample items for each included: 'The environment is risky; one false step can mean my organization's undoing' and
'Our organization must frequently change its practices to keep up with the market and competitors.' Respondents were asked to answer these questions on a sevenpoint scale (1: 'not at all' to 7: 'very much'). Similarly, firm size (measured by the number of full-time employees) and firm age (in terms of years) are controlled. When industry and country dummies were included with the other independent variables of the study, the results revealed non-significant findings. Therefore, they are not included in further analyses.

\section{Results}

\section{Descriptive statistics}

The authors used a database comprising 203 companies in Denmark (26), the Netherlands (46), Finland (13), Australia (19), Norway (8), Spain (18), Portugal (11), Slovakia (13), and Turkey (49). Company distribution regarding strategy and country shows that all countries but Spain, Norway, and Finland house all three strategy types. In all countries except Portugal and Slovakia, more than half of the firms pursue the analyzer strategy. Only $2 \%$ of the companies were pursuing reactor strategy, supporting the contention by Miles et al. (1978) that reactor method is not sustainable. Of these six reactors, which were excluded from the study, two were from Denmark, two from Turkey, one from Australia and one from the Netherlands. Company distribution regarding strategy and industry for 194 firms (down from 203 due to missing sector data) shows that the majority operate in the ICT (34), automotive (26), medical devices (26), electronics (20), telecommunications (18), and food (18) industries. The majority of prospectors operate in ICT (11), automotive (9), and telecommunications (8); the majority of analyzers in ICT (18), medical devices (17), and electronics (14); and the majority of defenders in ICT (5), automotive (4), medical devices (4), and food (4).

Tables 1, 2, and 3 show the means, standard deviations, and zero-order correlations among the variables for each strategy group respectively. Table 4 show the

Table 1 Means, standard deviations, and zero-order correlations for prospectors

\begin{tabular}{|c|c|c|c|c|c|c|c|c|c|c|}
\hline & $M$ & $S D$ & 1 & 2 & 3 & 4 & 5 & 6 & 7 & 8 \\
\hline 1. Hostility & 3.4 & 1.26 & & & & & & & & \\
\hline 2. Dynamism & 4.1 & 1.12 & $.42 * *$ & & & & & & & \\
\hline 3. Firm size & 922 & 3408 & -0.20 & -0.00 & & & & & & \\
\hline 4. Firm age & 32 & 33 & -0.05 & 0.04 & 0.27 & & & & & \\
\hline 5. NPD strategy formality & 5.15 & 1.17 & 0.05 & 0.17 & 0.23 & -0.05 & & & & \\
\hline 6. Sensing capabilities & 5.4 & 1.17 & -0.07 & 0.21 & 0.05 & -0.09 & $0.30 *$ & & & \\
\hline 7. Seizing capabilities & 5.2 & 1.21 & -0.07 & 0.10 & -0.01 & -0.21 & $0.45 * *$ & $0.54 * *$ & & \\
\hline 8. Reconfiguring capabilities & 4.9 & .86 & $-0.29 *$ & $-0.39 * *$ & 0.22 & -0.13 & $0.28 *$ & 0.14 & $0.34 * *$ & \\
\hline 9. NPD performance & 5.5 & 1 & 0.01 & 0.05 & 0.06 & 0.04 & $0.40 * *$ & $0.65^{* *}$ & $0.62 * *$ & 0.25 \\
\hline
\end{tabular}

$* p<0.05, * * p<0.01$. 
Table 2 Means, standard deviations, and zero-order correlations for analyzers

\begin{tabular}{|c|c|c|c|c|c|c|c|c|c|c|}
\hline & $M$ & $S D$ & 1 & 2 & 3 & 4 & 5 & 6 & 7 & 8 \\
\hline 1. Hostility & 3.5 & 1.18 & & & & & & & & \\
\hline 2. Dynamism & 3.7 & 1.23 & $0.40 * *$ & & & & & & & \\
\hline 3. Firm size & 889 & 3286 & 0.16 & -0.00 & & & & & & \\
\hline 4. Firm age & 33 & 33.8 & 0.01 & -0.04 & $0.29 * *$ & & & & & \\
\hline 5. NPD strategy formality & 5.03 & 1.19 & -0.04 & 0.11 & -0.11 & 0.06 & & & & \\
\hline 6. Sensing capabilities & 5.05 & 0.98 & $-0.20 *$ & -0.10 & -0.09 & 0.06 & $0.22 *$ & & & \\
\hline 7. Seizing capabilities & 4.92 & 0.90 & -0.13 & -0.00 & -0.11 & -0.15 & $0.28 * *$ & $0.27 * *$ & & \\
\hline 8. Reconfiguring capabilities & 4.67 & 0.86 & -0.09 & -0.13 & $-0.28 * *$ & 0.00 & $0.40 *$ & $0.36 * *$ & $0.56^{* *}$ & \\
\hline 9. NPD performance & 5.35 & 0.88 & -0.04 & -0.03 & -0.11 & 0.13 & $0.39 * *$ & $0.50 * *$ & $0.40 * *$ & $0.40 * *$ \\
\hline
\end{tabular}

${ }^{*} p<0.05, * * p<0.01$.

Table 3 Means, standard deviations, and zero-order correlations for defenders

\begin{tabular}{|c|c|c|c|c|c|c|c|c|c|c|}
\hline & $M$ & $S D$ & 1 & 2 & 3 & 4 & 5 & 6 & 7 & 8 \\
\hline 1. Hostility & 3.94 & 1.18 & & & & & & & & \\
\hline 2. Dynamism & 3.92 & 1.12 & $.62 * *$ & & & & & & & \\
\hline 3. Firm size & 1001 & 2983 & -0.14 & $-0.41 *$ & & & & & & \\
\hline 4. Firm age & 32 & 25 & 0.17 & 0.02 & $0.42 *$ & & & & & \\
\hline 5. NPD strategy formality & 4.7 & 1.14 & 0.05 & 0.28 & 0.11 & 0.18 & & & & \\
\hline 6. Sensing capabilities & 4.5 & 1.11 & -0.19 & 0.05 & 0.13 & 0.06 & 0.34 & & & \\
\hline 7. Seizing capabilities & 5.0 & 0.71 & 0.07 & 0.26 & 0.08 & -0.28 & $0.48 *$ & 0.27 & & \\
\hline 8. Reconfiguring capabilities & 4.57 & 0.94 & 0.09 & 0.26 & 0.09 & -0.13 & $0.41 *$ & 0.18 & $0.62 * *$ & \\
\hline 9. NPD performance & 5.1 & 1.07 & 0.19 & 0.28 & 0.16 & 0.17 & $0.46^{*}$ & $0.59 * *$ & 0.30 & 0.28 \\
\hline
\end{tabular}

$* p<0.05, * * p<0.01$.

Table 4 Means, standard deviations, zero-order correlations, and reliabilities for the whole sample

\begin{tabular}{|c|c|c|c|c|c|c|c|c|c|c|c|}
\hline & $M$ & $S D$ & 1 & 2 & 3 & 4 & 5 & 6 & 7 & 8 & \\
\hline 1. Hostility & 3.6 & 1.20 & (.44) & & & & & & & & \\
\hline 2. Dynamism & 3.9 & 1.18 & $.42 * *$ & $(0.60)$ & & & & & & & \\
\hline 3. Firm size & 895 & 3208 & -0.02 & -0.05 & & & & & & & \\
\hline 4. Firm age & 33 & 30 & .00 & -0.00 & $0.29 * *$ & & & & & & \\
\hline 5. NPD strategy formality & 5.0 & 1.22 & -0.04 & 0.12 & 0.00 & 0.04 & $(0.88)$ & & & & \\
\hline 6. Sensing capabilities & 5.1 & 1.07 & $-0.18^{*}$ & 0.00 & -0.02 & -0.00 & $0.29 * *$ & $(0.84)$ & & & \\
\hline 7. Seizing capabilities & 5.0 & 0.99 & -0.11 & 0.05 & -0.06 & $-0.18^{*}$ & $0.39 * *$ & $0.38 * *$ & $(0.82)$ & & \\
\hline 8. Reconfiguring capabilities & 4.7 & 0.90 & $-0.16^{*}$ & $-0.16^{*}$ & -0.09 & -0.05 & $0.41 * *$ & $0.29 * *$ & $0.49 * *$ & $(0.83)$ & \\
\hline 9. NPD performance & 5.4 & 0.94 & 0.00 & 0.04 & -0.02 & 0.09 & $0.40 * *$ & $0.58 * *$ & $0.47 * *$ & $0.30 * *$ & $(0.80)$ \\
\hline
\end{tabular}

$* p<0.05, * * p<0.01$.

Reliabilities (Cronbach's alpha) are reported in parentheses.

means, standard deviations, and zero-order correlations among the variables for the whole sample. Accordingly, components of dynamic capabilities (sensing, seizing, reconfiguring) show moderate relationships with each other, ranging between 0.29 and 0.49. $(p<0.01)$. More importantly, NPD strategy formality and dynamic capabilities both have moderate relationships with NPD performance; 0.40 for the former and ranging between 0.30 and 0.58 for the latter $(p<0.01)$.

\section{Preliminary analyses}

The authors used multi-item scales for each construct in this study, and prior to creating the final scales, checked the data for normality and outliers. Several methods refined the measures and assessed their construct validity. First, the authors ran exploratory analyses for the dynamic capabilities scale, which resulted in theoretically predicted factor solutions. They conducted factor analysis with a varimax rotation for 18 items representing dynamic capabilities. The explained variances by the first factor (reconfiguring capabilities), second factor (seizing capabilities), and third factor (sensing capabilities) resulted in $35.25 \%, 19.92 \%$, and $16.93 \%$, respectively. The total variance explained by these three factors resulted in $72.10 \%$. Second, the authors ran reliability analyses (Cronbach's alpha) for all constructs, which were all above the accepted level of 0.70 (except for 
hostility and dynamism; but because these variables are control variables, they remain in the analysis). Third, to assess whether common method variance might be a problem, the authors applied Harman's single-factor test (Podsakoff and Organ, 1986). The presence of six factors with Eigenvalues greater than one, and with the first factor accounting for only $31 \%$ of the variance suggests that common method bias is unlikely to be a concern.

To assess non-response bias, the authors conducted a test for comparing the averages of annual sales and the number of employees of early and late respondents (Armstrong and Overton, 1977). Because the data collection began at the same time in all countries, the responses were pooled initially and then sorted based on the date they were received. The t-tests between the mean responses of early and late respondents indicate no statistically significant differences at the 0.05 level. Overall, non-response bias in the data is not a concern.

\section{Findings}

Each of the independent variables was regressed on NPD performance alone before they were included together in the hypothesis testing. The analyses revealed significant relationships between each independent variable and NPD performance $(\beta=0.43, p<0.001$ for NPD strategy formality; $\beta=0.63, p<0.001$ for sensing capabilities; $\beta=0.50, p<0.001$ for seizing capabilities; and $\beta=0.30, p<0.001$ for reconfiguration capabilities). Furthermore, to see if splitting the data has any merit we regressed controls together with dummies for business strategy (prospectors taken as the reference group) on NPD performance. ${ }^{1}$ As can be seen from Table 5, analyzers, defenders and reactors have significantly lower scores for the dependent as compared to the prospectors.

The authors tested the hypotheses using ordinary least squares regression within subgroups. Subgroup analysis is an appropriate technique to test for moderation when the moderator variable is categorical (Sharma et al., 1981). To determine the relative impact of NPD strategy formality and dynamic capabilities in NPD on NPD performance for alternative strategies, the authors conducted hierarchical regression analysis, controlling for environmental hostility, dynamism, firm age, and size. In Step 1 of the hierarchical regression analysis, the authors entered the control variables; in Step 2 they entered NPD strategy formality; and in Step 3 entered dynamic capabilities in NPD (sensing, seizing, and reconfiguring). Table 6 summarizes the results. For comparisons, we examined the difference in magnitude of the relationship

\footnotetext{
${ }^{1}$ We thank the anonymous reviewer for his/her scholarly perspective and guidance.
}

Table 5 Regression with strategy dummies (analyzers, defenders, reactors) on the NPD performance (in terms of radical-next generation product sales)

\begin{tabular}{|c|c|c|c|c|}
\hline & \multicolumn{2}{|c|}{$\begin{array}{l}\text { Unstandardized } \\
\text { coefficients }\end{array}$} & \multirow{2}{*}{$\begin{array}{l}\begin{array}{l}\text { Standardized } \\
\text { coefficients }\end{array} \\
\text { Beta }\end{array}$} & \multirow[b]{2}{*}{$t$} \\
\hline & $B$ & Std. Error & & \\
\hline Constant & 62.505 & 8.417 & & 7.426 \\
\hline Hostility & -0.281 & 1.720 & -0.01 & -0.163 \\
\hline Dynamism & -0.340 & 1.783 & -0.01 & -0.191 \\
\hline Firm age & -0.130 & 0.060 & $-0.15^{*}$ & -2.174 \\
\hline Firm size & 0.000 & 0.001 & -0.02 & -0.306 \\
\hline Analyzers $^{\mathrm{a}}$ & -24.56 & 4.444 & $-0.43 * * *$ & -5.526 \\
\hline Defenders ${ }^{b}$ & -23.20 & 6.480 & $-0.28 * * *$ & -3.580 \\
\hline Reactors $^{\mathrm{c}}$ & -28.15 & 11.167 & $-0.18 * *$ & -2.520 \\
\hline $\mathrm{R}^{2}$ & & & & 0.18 \\
\hline Adjusted $\mathrm{R}^{2}$ & & & & 0.15 \\
\hline F-value & & & & $5.7 * * *$ \\
\hline
\end{tabular}

$* p<0.05, * * p<0.01, * * * p<0.001$.

${ }^{\mathrm{a} A n a l y z e r}=1$ if the SBU is classified as an Analyzer, 0 if not.

${ }^{\mathrm{b}}$ Defender $=1$ if the SBU is classified as a Defender, 0 if not.

${ }^{\mathrm{c}}$ Reactors have all the dummy variables $=0$. (Reactors shown in the table but not used in hypothesis testing).

between the predictor and the criterion variable for each pair of strategy types (Cohen et al., 2003; Slater et al., 2006).

\section{NPD strategy formality}

For analyzers and defenders, as expected, the authors find a positive effect of NPD strategy formality on NPD performance in Step 2 and $3(\beta=0.22, p<0.05$; from Step 2 to Step $3, \Delta \mathrm{R}^{2}=0.22, \mathrm{p}<0.001$ for analyzers, $\beta=0.55, p<0.05$; from Step 2 to Step $3, \Delta \mathrm{R}^{2}=0.34$, $\mathrm{p}<0.01$ for defenders). For prospectors, there is a positive effect of NPD strategy formality on NPD performance in Step $2(\beta=0.42, p<0.01$; from Step 1 to Step $\left.2, \Delta R^{2}=0.12, p<0.01\right)$, however, this effect looses its significance in Step 3 when dynamic capabilities are added to the analyses. Hence, Hypothesis 1 is partially supported.

\section{Dynamic capabilities}

As predicted, the authors identify a positive effect of sensing capabilities on NPD performance for prospectors $(\beta=0.50, p<0.001)$ (from Step 2 to Step 3, $\left.\Delta R^{2}=0.46, p<0.001\right)$. Sensing capabilities were also found to have a significant effects on NPD performance for defenders $(\beta=0.58, \quad p<0.01)$ and analyzers $(\beta=0.38, p<0.001)$ (from Step 2 to Step $3, \Delta \mathrm{R}^{2}=0.34$, $\mathrm{p}<0.01$ for defenders and $\Delta \mathrm{R}^{2}=0.22, \mathrm{p}<0.001$ for analyzers). While this effect is stronger for prospectors $(\beta=0.50, p<0.001))$ than for analyzers $(\beta=0.38$, $p<0.001)$, the difference between prospectors and defenders $(\beta=0.58, p<0.01)$ is not significant. Hence, Hypothesis 2 is partially supported. 
Table 6 Business strategies: regression results for NPD performance as the criterion variable

\begin{tabular}{|c|c|c|c|}
\hline \multicolumn{4}{|l|}{ Business Strategies } \\
\hline & $\begin{array}{l}\text { Prospectors } \\
(n=58)\end{array}$ & $\begin{array}{l}\text { Analyzers } \\
(n=119)\end{array}$ & $\begin{array}{l}\text { Defenders } \\
(n=26)\end{array}$ \\
\hline \multicolumn{4}{|l|}{ Variables } \\
\hline \multicolumn{4}{|l|}{ Step 1} \\
\hline Hostility & $-0.03(0.13)^{\mathrm{a}}$ & $-0.03(0.07)$ & $0.06(0.26)$ \\
\hline Dynamism & $0.08(0.15)$ & $-0.09(0.07)$ & $0.21(0.30)$ \\
\hline Firm size & $0.04(0.00)$ & $-0.05(0.00)$ & $0.23(0.00)$ \\
\hline Firm age & $0.03(0.03)$ & $0.16(0.00)$ & $-0.12(0.01)$ \\
\hline $\mathrm{R}^{2}$ & 0.05 & 0.07 & 0.17 \\
\hline Adjusted $\mathrm{R}^{2}$ & -0.09 & 0.02 & -0.07 \\
\hline F-value & 0.10 & 1.51 & 0.70 \\
\hline \multicolumn{4}{|l|}{ Step 2} \\
\hline Hostility & $-0.02(0.12)$ & $0.02(0.06)$ & $0.14(0.24)$ \\
\hline Dynamism & $0.00(0.14)$ & $-0.16(0.06)$ & $0.04(0.35)$ \\
\hline Firm size & $0.00(0.00)$ & $-0.11(0.00)$ & $0.16(0.00)$ \\
\hline Firm age & $0.08(0.00)$ & $0.15(0.00)$ & $-0.14(0.01)$ \\
\hline NPD strategy formality & $\mathbf{0 . 4 2} * *(0.12)$ & $\mathbf{0 . 4 2} * * *(0.06)$ & $\mathbf{0 . 7 1} *(0.24)$ \\
\hline $\mathrm{R}^{2}$ & 0.18 & 0.24 & 0.42 \\
\hline Adjusted $\mathrm{R}^{2}$ & 0.07 & 0.20 & 0.20 \\
\hline F-value & 1.85 & $5.39 * * *$ & 1.95 \\
\hline$\Delta \mathrm{R}^{2}$ (from Step 1 to 2 ) & $0.12 * *$ & $0.18 * * *$ & $0.25^{*}$ \\
\hline \multicolumn{4}{|l|}{ Step 3} \\
\hline Hostility & $0.12(0.09)$ & $0.09(0.05)$ & $0.23(0.17)$ \\
\hline Dynamism & $-0.12(0.11)$ & $-0.10(0.05)$ & $-0.04(0.28)$ \\
\hline Firm size & $-0.01(0.00)$ & $-0.02(0.00)$ & $0.22(0.00)$ \\
\hline Firm age & $0.24 *(0.00)$ & $0.11(0.00)$ & $-0.21(0.00)$ \\
\hline NPD strategy formality & $0.04(0.10)$ & $\mathbf{0 . 2 2} *(0.05)$ & $\mathbf{0 . 5 5} *(0.18)$ \\
\hline Sensing capabilities & $\mathbf{0 . 5 0}^{* * *}(0.11)$ & $\mathbf{0 . 3 8} * * *(0.06)$ & $\mathbf{0 . 5 8} * *(0.14)$ \\
\hline Seizing capabilities & $\mathbf{0 . 4 2} * *(0.11)$ & $\mathbf{0 . 2 4} *(0.08)$ & $0.06(0.35)$ \\
\hline Reconfiguring capabilities & $0.00(0.14)$ & $0.10(0.09)$ & $\mathbf{0 . 3 6}^{\dagger}(0.20)$ \\
\hline $\mathrm{R}^{2}$ & 0.64 & 0.46 & 0.76 \\
\hline Adjusted $\mathrm{R}^{2}$ & 0.57 & 0.41 & 0.60 \\
\hline F-value & $8.55^{* * *}$ & $9.27 * * *$ & $4.53 * *$ \\
\hline$\Delta \mathrm{R}^{2}$ (from Step 2 to 3 ) & $0.46^{* * *}$ & $0.22 * * *$ & $0.34 * *$ \\
\hline
\end{tabular}

${ }^{\mathrm{a} N u m b e r s ~ i n ~ p a r e n t h e s e s ~ a r e ~ c o e f f i c i e n t ~ s t a n d a r d ~ d e v i a t i o n s . ~}$ ${ }^{*} p<0.05,{ }^{* *} p<0.01,{ }^{* * *} p<0.001,{ }^{\dagger} p=0.07$.

As predicted, the authors identify a stronger positive effect of seizing capabilities on NPD performance for prospectors $(\beta=0.42, p<0.01)$ and analyzers $(\beta=0.24$, $p<0.05)$, than for defenders. This relationship is not significant for defenders. Thus, Hypothesis 3 is supported. The effect of reconfiguring capabilities on NPD performance is not significant for prospectors and analyzers, whereas it shows a tendency for defenders ( $\mathrm{p}=0.07$, Table 6). Hence, Hypothesis 4 is partially supported.

Adding dynamic capabilities to the model in Step 3, the authors observe significant $R^{2}$ changes from Step 2 to Step 3 for all strategy types $\left(\Delta \mathrm{R}^{2}=0.46, \mathrm{p}<0.001\right.$ for prospectors, $\Delta \mathrm{R}^{2}=0.22, \mathrm{p}<0.001$ for analyzers and $\Delta R^{2}=0.34, p<0.01$ for defenders). NPD strategy formality significant in Step 2 for all strategy types, decreases in terms of magnitude and significance for analyzers and defenders, while loses its significance for prospectors. This supports the expectation that dynamic capabilities have explanatory power above and beyond that of a strong NPD strategy for all strategy types, most significantly for prospectors.

\section{Discussion and conclusions}

The study provides important contributions to the literature by investigating the effects of NPD strategy formality and dynamic capabilities on NPD performance for different business strategies. First, the findings show that the effects of NPD strategy formality and dynamic capabilities on NPD performance vary depending on a firm's business strategy. Given that firms have different priorities around responding to their environment, the degree to which they focus on a formal strategy, and capability development differ, so do their performance effects. Second, the study provides empirical evidence for the stronger explanatory power of dynamic capabilities compared to strategizing. The overriding performance effects of such capabilities are evident irrespective of the 
type of business strategy pursued. In these respects, the present study makes important contributions to the strategy literature. Third, the study examines strategy formality and the components of dynamic capabilities, taking NPD as the unit of analysis; previous studies mostly focus on the effects of these factors at the organizational level. This study contributes to the product development literature especially by investigating dynamic capabilities in an NPD context because developing such capabilities is significant in developing competitive new products in addition to existing success factors (Danneels, 2002; Marsh and Stock, 2003; Prieto et al., 2009).

As expected, the study identifies that a formal NPD strategy is an important driver of NPD success for analyzers and defenders, and it unexpectedly finds that such a strategy is also important for prospectors. For prospectors, the positive link between NPD strategy formality and performance is inconsistent with Veliyath and Shortell (1993) and Slater et al. (2006). This inconsistency might stem from the unit of analysis; while those two studies investigate the effects of strategy formalization at the business unit level, the current study focuses on the NPD unit. This inconsistency may also be due to the different samples under investigation; while the above-noted studies examine US firms, the current study focuses on European firms. As suggested by recent research (Kirca et al., 2005; Acur et al., 2012), US firms prefer short-term payoffs while European firms, such as in Denmark, Norway, the Netherlands, and Finland, are more comfortable with long-term strategic orientations. This finding of the present study supports Shortell and Zajac's (1990) study, which reports that strategy formalization is positively related to innovation for prospectors. Hence, the authors suggest that 'formality should not be considered synonymous with a rigidity that might restrict the ability of prospectors to respond to a quickly changing market' (Shortell and Zajac, 1990: 828). Accordingly, for prospectors a formal NPD strategy may provide the basis for deciding which new opportunities should be pursued and integrated. Notably, as will be explained below, for prospectors the positive performance effect of NPD strategy formality becomes insignificant in the presence of dynamic capabilities.

Sensing capabilities have been identified to have significant effects on NPD performance for all three strategy types. While, as expected, these capabilities have stronger effects for prospectors than for analyzers, unexpectedly, the effect for prospectors is not significantly stronger than for defenders. In other words, sensing capabilities are found to be strong drivers of NPD performance for defenders as well. This result for defenders is not consistent with much of the previous research (e.g., Hambrick, 1983), but may coincide with some recent studies. For example, Laugen et al. (2006) show that all three types of companies need to emphasize monitoring the market for opportunities. Ellonen et al. (2009) suggest that sensing capabilities are a prerequisite for generating innovation and for survival in dynamic markets. These contentions may find support in today's increasingly competitive markets; even defenders may now be under increasing pressure to identify and integrate opportunities to protect their domains.

In line with our expectations, seizing capabilities have significant performance effects for prospectors and analyzers, than for defenders. This finding is in line with Conant et al. (1990). Prospectors and analyzers both seek to develop capabilities around the engineering problem. Prospectors tend to develop radical innovations that usually require building new capabilities rather than reconfiguring old ones that have worked well for previous products/technologies. Those new capabilities are most often built in a separate entity or subsidiary so they will not play against the old competences. Such 'ambidextrous organizations,' that is, with differentiated but partially or weakly integrated subunits (O'Reilly and Tushman, 2004), may be common to analyzers as well, who need to create new competences within new units but preserve their old competences within their established units. Miles and Snow (1978) note that analyzers face an engineering problem that includes improving technological competences and complementary assets while retaining a base of traditional segments and competences. Hence, analyzers must also acquire new competences and develop a shared understanding of them through their functional units to be able to follow prospectors.

Reconfiguring capabilities have significant performance effects only for defenders. This finding suggests that agressively maintaining their domain through competitive pricing, as suggested by Miles et al. (1978), is a viable strategy for these companies. However, contrary to the current study's expectations, for analyzers this relationship is insignificant. Although Ellonen et al. (2009) suggest that analyzer firms are better able to leverage their existing capabilities and reconfigure their competences, this study finds that those capabilities do not enhance analyzers' NPD performances. Instead, these companies might maintain their domains through offering new products not only to their more dynamic markets but also to their existing markets. Analyzers' NPD performance might be increasingly dependent on their sensing and seizing capabilities, as this study also identifies.

Notably, another contribution of the study is that it employes a measure of dynamic capabilities which fully covers the three dimensions defined by Teece (2007). Of those previous studies which examine dynamic capabilities, only a limited number are empirical investigations, and their coverage of dynamic capabilities is incomplete. For example, these studies operationalize dynamic capabilities in terms of research team capabilities and R\&D management capabilities (Deeds et al., 1999), 
knowledge retention, interpretation and integration of prior knowledge (Marsh and Stock, 2003) and knowledge generation, integration and reconfiguration capabilities (Prieto et al., 2009). To this end, the present study, by adopting a more comprehensive approach to the measurement of dynamic capabilities contributes to the field, which is still in its infancy, with overlapping definitions, measures, and inconsistencies (Zahra et al., 2006; $\mathrm{Wu}, 2010)$.

\section{Concluding remarks, future research, and managerial implications}

Most study findings support Laugen et al. (2006), who show that the three strategy types are growing towards each other, that is, differences between companies in terms of their competitive priorities and the systems they use to support their functioning may be disappearing. Laugen et al. (2006) point out that when Miles and Snow published their work in 1978, competition was mostly price based; today's companies need to develop new capabilities in terms of market, technology, variety, speed, and, increasingly, innovation (Ellonen et al., 2009). Parallel to this view, sensing capabilities are noted in the present study as dynamic capabilities with strong performance effects not only for prospectors but also for defenders. Perhaps traditional defenders, who are mechanistic and efficiency-seeking, are less likely to survive in most industries today, at least in those facing global and competitive forces. Defenders must now also seek opportunities and focus on new products in their NPD efforts to improve performance. Similarly, the study finds that for analyzers, sensing capabilities are important drivers of NPD performance, although to a lesser extent when compared to prospectors. This finding parallels Desarbo et al. (2005), who, based on data from 709 firms in three countries, find that analyzers do not necessarily constitute a separate group, but behave as prospectors or defenders. Considering the current study's results, such companies may be moving closer to prospectors if the Miles and Snow typology is viewed as a continuum (Olson et al., 2005). As also suggested by McKee et al. (1989), a firm may show strategic flexibility and move toward an adjacent strategy type. Supporting these contentions, analyzers in this study may be moving closer to prospectors, and defenders may be moving closer to analyzers, given the apparent importance of sensing capabilities in generating higher performance.

The current study's findings call for future research to investigate (1) the effects of sensing capabilities on defenders' performance at the organizational level, (2) whether analyzers are approaching prospectors and defenders are approaching analyzers with respect to behaviors other than dynamic capability development, and (3) the role of other components of strategic management, for example, analyzing situations and evaluating strategic alternatives (Slater et al., 2006), as well as the role of strategic implementation (Veliyath and Shortell, 1993) in NPD performance for different business strategies.

Importantly, the present study finds that dynamic capabilities explain NPD performance above and beyond a formal NPD strategy, regardless of the type of strategy pursued. That is, in the presence of dynamic capabilities, a formal NPD strategy has much less effect on NPD performance. For prospectors, the performance effect of a strong NPD strategy is no more significant when it coexists with dynamic capabilities. These findings provide empirical evidence for Teece et al.'s (1997) theoretical suggestions, which postulate that competitive advantage stems from investing in soft assets, that is, highperformance routines shaped by processes, positions, and paths, rather than from strategizing about how best to take advantage of competitors' limitations or firm resources. The authors argue that 'except in special circumstances, too much "strategizing" can lead firms to underinvest in core competences and neglect dynamic capabilities, and thus, harm long-term competitiveness' (Teece et al., 1997: 528). Similarly, Pitt and Clarke (1999) suggest that competitive environments in the new millennium challenge firm behavior in that firms increasingly need fluid, directed, yet adaptive learning to prosper. Simultaneously examining NPD strategy formality and dynamic capabilities in the present study enabled validating the contention that in NPD settings dynamic capabilities have stronger performance effects than strategizing. Future research in the strategy area and dynamic capabilities stream should provide empirical evidence from contexts other than NPD to lend further support to the overriding effects of the capabilities view.

This study has several limitations. First, it is based on cross-sectional data, therefore the relationships are correlational and do not show cause and effect. Future research should employ longitudinal data, if possible. Second, prior performance of companies is not measured in the study. With such data, it may also be possible to observe changes in the NPD performance of companies as they develop dynamic capabilities over time. As some scholars have also suggested, even small differences in dynamic capabilities among firms over time can result in differential firm performance (Adler and Helfat, 2003; Zott, 2003). Third, the sample size for defenders is small, suggesting that the related findings should be taken into consideration cautiously and should be further explored in future studies. This is a common problem for studies conducting subgroup analysis in the business strategy area (e.g., Di Benedetto and Song, 2003; Olson et al., 2005; Song et al., 2007). To explore further on this limitation, as suggested by Cohen and colleagues (2003), we conducted a power analysis to determine the probability of finding the sample $\mathrm{R}^{2}$ to be greater than zero with $\alpha=0.05$. For a medium effect size ( $f=0.25$, 
the minimum sample size for a subgroup is suggested to be 27 . Hence, for the defenders group in this study we can talk about small to medium effects.

Fourth, the data is collected from a single source, but to increase objectivity and measurement robustness, the authors use the self-typing approach and additional quantitative criteria to identify the business strategies. Although Harman's test shows that common-method bias is unlikely to be a problem, the authors suggest obtaining data from multiple sources in future studies. Finally, the study is conducted on European firms; research from non-European countries is required to generalize the results.

The findings have several implications for company and NPD managers. A strong and formal NPD strategy with clearly defined product concept definitions and goals based on a systematic project portfolio will provide strategic direction for firms' NPD activities. More importantly, identifying and integrating opportunities are crucial for a competitive NPD function, regardless of the strategy used. Developing sensing capabilities necessitates activities and investments such as collecting feedback from lead users, customers, suppliers, and distributors; carefully analyzing users' problems and using feedback as opportunities for NPD; conducting research to analyze changing customer needs and markets; participating in conferences, seminars, and technology fairs; building close ties and collaborating with universities; and investing in R\&D (See Giuri et al, 2007 for the results from the PATVal-EU survey). Companies should assign gatekeeping or boundary-spanning activities to employees according to their specializations and include such responsibilities in their job descriptions to increase motivation and achieve company objectives. Firms should also seek and share new knowledge and ideas internally where they can encourage and facilitate cross-functional integration and intra-organizational communication, organize seminars within the company, and use idea-generating techniques and methods with internal and external stakeholders. To help build and enhance sensing capabilities, firms can establish objectives that explicitly target identifying and integrating opportunities and developing performance metrics favoring collaboration and teamwork, creativity, and innovative behavior. In order to achieve a sustainable competitive advantage in today's business world, managers should not only focus on strategizing, but also on developing dynamic capabilities, most crucially sensing capabilities.

\section{References}

Acur, N., D. Kandemir and H. Boer, 2012, "Strategic alignment and new product development: Drivers and performance effects". Journal of Product Innovation Management, 29: 304-318.
Acur, N., D. Kandemir, P. Weerd-Nederhof and M. Song, 2010, "Exploring the impact of technological competence development on speed, and NPD program performance". Journal of Product Innovation Management, 27: 915-928.

Adler, R. and C. E. Helfat, 2003, "Corporate effects and dynamic managerial capabilities". Strategic Management Journal, 24: 1011-1025.

Armstrong, J. S. and T. S. Overton, 1977, "Estimating nonresponse bias in mail surveys". Journal of Marketing Research, 14: 396-402.

Augier, M. and D. J. Teece, 2007, "Dynamic capabilities and multinational enterprise: Penrosean insights and omissions". Management International Review, 47: 175-192.

Bantel, K. A., 1998, “Technology-based, 'adolescent' firm configurations: Strategy identification, context, and performance". Journal of Business Venturing, 13: 205-230.

Brews, P. J. and M. R. Hunt, 1999, "Learning to plan and planning to learn: Resolving the planning school/learning school debate". Strategic Management Journal, 20: 889913.

Brown, S. L. and K. M. Eisenhardt, 1995, "Product development: Past research, present findings and future directions". Academy of Management Review, 20: 343-378.

Calantone, R., R. Garcia and C. Droge, 2003, "The effects of environmental turbulence on new product development strategy planning". Journal of Product Innovation Management, 20: $90-103$.

Cepeda, G. and D. Vera, 2007, "Dynamic capabilities and operational capabilities: A Knowledge management perspective". Journal of Business Research, 60: 426-437.

Chiesa, V., P. Coughlan and C. A. Voss, 1996, "Development of a technical innovation audit". Journal of Product Innovation Management, 13: 105-136.

Churchill, G., 1979, “A paradigm for developing better measures of marketing constructs". Journal of Marketing Research, 16: 64-73.

Clark, K. B. and S. C. Wheelwright, 1993, Managing new product and process development. New York: The Free Press.

Cohen, J., P. Cohen, S. G. West and L. S. Aiken, 2003, Applied multiple regression/correlation analysis for the behavioral sciences, 3d edn, Mahwah, NJ: Lawrence Erlbaum.

Cohen, W. and D. Levinthal, 1990, "Absorptive capacity: A new perspective on learning and innovation". Administrative Science Quarterly, 35: 128-152.

Conant, J. S., M. P. Mokwa and P. R. Varadarajan, 1990, "Strategic types, distinctive marketing competencies and organizational performance: A multiple-measures-based study". Strategic Management Journal, 11: 365-383.

Cooper, R. G., S. J. Edgett and E. J. Kleinschmidt, 2004, "Benchmarking best NPD practices-II: Strategy, resource allocation and portfolio management". Research-Technology Management, 47: 50-59.

Cooper, R. G. and E. J. Kleinschmidt, 1995, "Benchmarking the firm's critical success factors in new product development". Journal of Product Innovation Management, 12: 374 391.

Danneels, E., 2002, "The dynamics of product innovation and firm competences". Strategic Management Journal, 23: 10951121.

Day, G. S., 1994, “The capabilities of market-driven organizations". Journal of Marketing, 58: 37-52. 
De Brentani, U. and E. J. Kleinschmidt, 2004, "Corporate culture and commitment: Impact on performance of international new product development programs". Journal of Product Innovation Management, 21: 309-333.

Deeds, D. L., D. Decarolis and J. Coombs, 1999, "Dynamic capabilities and new product development in high technology ventures: An empirical analysis of new biotechnology firms". Journal of Business Venturing, 15: 211-229.

Desarbo, W. S., C. A. Di Benedetto, M. Song and I. Sinha, 2005, "Revisiting Miles and Snow strategic framework: Uncovering interrelationships between strategic types, capabilities, environmental uncertainty, and firm performance". Strategic Management Journal, 26: 47-74.

Di Benedetto, C. A. and M. Song, 2003, "The relationship between strategic type and firm capabilities in Chinese firms". International Marketing Review, 20: 514-533.

Dillman, D. A., 2000, Mail and internet surveys: The tailored design method. New York: John Wiley \& Sons.

Dougherty, D., L. Borrelli, K. Munir and A. O'Sullivan, 2000, "Systems of organizational sensemaking for sustained innovation". Journal of Engineering and Technology Management, 17: 321-355.

Dvir, D., E. Segev and A. Shenhar, 1993, “Technology's varying impact on the success of strategic business units within the Miles and Snow typology". Strategic Management Journal, 14: 155-162.

Easterby-Smith, M. and I. M. Prieto, 2008, "Dynamic capabilities and knowledge management: An integrative role for learning?" British Journal of Management, 19: 235-249.

Ellonen, H. K., P. Wikström and A. Jantunen, 2009, "Linking dynamic-capability portfolios and innovation outcomes". Technovation, 29: 753-762.

Eisenhardt, K. M. and J. A. Martin, 2000, "Dynamic capabilities: What are they?". Strategic Management Journal, 21: 1105-1121.

Fredrickson, J. W. and T. R. Mitchell, 1984, "Strategic decision processes: Comprehensiveness and performance in an industry with an unstable environment". Academy of Management Journal, 27: 399-423.

Fiegenbaum, A. and H. Thomas, 2004, "Strategic risk and competitive advantage: An integrative perspective". European Management Review, 1: 84-95.

Gatignon H. and J.-M. Xuereb, 1997, "Strategic alignment of the firm and new product development performance". Journal of Marketing Research, 34: 77-90.

Giuri, P., M. Mariani, S. Brusoni, G. Crespi, D. Francoz, A. Gambardella et al., 2007, "Inventors and invention processes in Europe: Results from the PatVal-EU survey". Research Policy, 36: 1107-1127.

Griffin, A., 1997, "Modeling and measuring product development cycle time across industries". Journal of Engineering and Technology Management, 14: 1-24.

Griffin, A. and A. L. Page, 1993, "An interim report on measuring product development success and failure". Journal of Product Innovation Management, 10: 291-308.

Hambrick, D., 1983, "Some tests of the effectiveness and functional attributes of Miles and Snow's strategic types". Academy of Management Journal, 26: 5-26.

Hambrick, D., 2003, "On the staying power of Miles and Snow's defenders, analyzers, and prospectors". Academy of Management Executive, 17: 115-118.
Harreld, J. B., C. A. O'Reilly III and M. L. Tushman, 2007, "Dynamic capabilities at IBM: Driving into action". California Management Review, 49: 21-43.

Johnson, J. L., R. Pui-Wan Lee, A. Saini and B. Grohmann, 2003, "Market-focused strategic flexibility: Conceptual advances and an integrative model". Journal of the Academy of Marketing Science, 31: 74-89.

Kandemir, D. and N. Acur, 2012, "Examining proactive strategic decision-making flexibility in new product development", Journal of Product Innovation Management, 29: 608622.

Kessler, E. H., P. E. Bierly and S. Gopalakrishnan, 2000, "Internal vs. external learning in new product development: Effects on speed, cost and competitive advantage". $R \& D$ Management, 30: 213-223.

Kirca, A. H., S. Jayachandran and W. O. Bearden, 2005, "Market orientation: A meta-analytic review and assessment of its antecedents and impact on performance". Journal of Marketing, 69: 24-41.

Koufteros, X. A., M. A. Vonderembse and W. J. Doll, 2002, "Integrated product development practices and competitive capabilities: The effects of uncertainty, equivocally, and platform strategy". Journal of Operations Management, 20: 331355.

Kyrgidou, L. P. and S. Spyropoulou, 2012, "Drivers and performance outcomes of innovativeness: An empirical study". British Journal of Management, 24: 281-298.

Laugen, B. T., H. Boer and N. Acur, 2006, "The new product development improvement motives and practices of Miles and Snow's prospectors, analysers and defenders". Creativity and Innovation Management, 15: 85-95.

Marsh, S. J. and G. N. Stock, 2003, "Building dynamic capabilities in new product development through inter-temporal integration". Journal of Product Innovation Management, 20: 136-148.

Matsuno, K. and J. T. Mentzer, 2000, "The effects of strategy type on the market orientation-performance relationship". Journal of Marketing, 64: 1-16.

McKee, D. O., P. V. Varadarajan and W. M. Pride, 1989, "Strategic adaptability and firm performance: A marketcontingent perspective". Journal of Marketing, 53: 2135.

Miles, R. E. and C. C. Snow, 1978, Organizational strategy, structure, and process. New York: McGraw Hill.

Miles, R. E., C. C. Snow, A. D. Meyer and H. J. Coleman, 1978, "Organizational strategy, structure, and process". Academy of Management Review, July: 546-562.

Mintzberg, H., 1990, "Strategy formation: Schools of thought". In J. W. Fredrickson (ed.) Perspectives on strategic management. New York: Harper Business, pp. 105-235.

Mintzberg, H., B. Ahlstrand and J. Lampel, 1998, Strategy safari. New York: Free Press.

Narver J. C., S. F. Slater and D. L. MacLachlan, 2004, "Responsive and proactive market orientation and newproduct success". Journal of Product Innovation Management, 21: 334-347.

O'Connor, G. C., 2008, "Major innovation as a dynamic capability: A systems approach". Journal of Product Innovation Management, 25: 313-30.

Olson, M. E., S. F. Slater and G. T. M. Hult, 2005, "The performance implications of fit among business strategy, 
marketing organization structure, and strategic behavior". Journal of Marketing, 69: 49-65.

O'Reilly, C. A., III and M. L. Tushman, 2004, "The ambidextrous organization". Harvard Business Review, 82: 74-81.

Parry, M. E., M. Song, P. C. de Weerd-Nederhof and K. Visscher, 2009, "The impact of NPD strategy, product strategy, and NPD processes on perceived cycle time". Journal of Product Innovation, 26: 627-639.

Pitt, M. and K. Clarke, 1999, "Competing on competence: A knowledge perspective on the management of strategic innovation", Technology Analysis \& Strategic Management, 11: 301-316.

Podsakoff, P. M. and D. W. Organ, 1986, "Self-reports in organizational research: Problems and prospects". Journal of Management, 12: 531-544.

Porter, M. E., 1980, Competitive strategy. Techniques for analyzing industries and competitors. New York: The Free Press.

Poulis, K. and P. Jackson, 2010, "Dynamic capabilities and conflicting goals: The case of competitive strategies". Paper presented at the annual meeting of the European Academy of Management, May, Rome.

Priem, R. L., A. M. A. Rasheed and A. G. Kotulic, 1995, "Rationality in strategic decision processes, environmental dynamism and firm performance". Journal of Management, 21: 913-929.

Prieto, I. M., E. Revilla and B. Rodriguez-Prado, 2009, "Building dynamic capabilities in product development: How do contextual antecedents matter?". Scandinavian Journal of Management, 25: 313-326.

Schulze, A. and G. J. C. Brojerdi, 2012, "The effect of the distance between partners' knowledge components on collaborative innovation". European Management Review, 9: 85-98.

Sharma, S., R. Durand and O. Gur-Arie, 1981, "Identification and analysis of moderator variables". Journal of Marketing Research, 18: 291-300.

Shoham A., F. Evangelista and G. Albaum, 2002, "Strategic firm type and export performance". International Marketing Review, 19: 236-258.

Shortell, S. M. and E. J. Zajac, 1990, "Perceptual and archival measures of Miles and Snow's strategic types: A comprehensive assessment of reliability and validity". Academy of Management Journal, 33: 817-832.

Siguaw, J. A., P. M. Simpson and C. A. Enz, 2006, "Conceptualizing innovation orientation: A framework for study and integration of innovation research". Journal of Product Innovation Management, 23: 556-574.

Slater, S. F., E. M. Olson and G. T. M. Hult, 2006, "The moderating effect of strategic formation capabilityperformance relationship". Strategic Management Journal, 27: 1221-1231.

Snow. C. C. and L. G. Hrebiniak, 1980, "Strategy, distinctive competence, and organizational performance". Administrative Science Quarterly, 25: 317-336.
Song, M., C. A. Di Benedetto, R. W. Nason, 2007, "Capabilities and financial performance: The moderating effect of strategic type". Journal of the Academy of Marketing Science, 35: 18-34.

Song, M., R. W. Nason and C. A. Di Benedetto, 2008, "Distinctive marketing and information technology capabilities and strategic types: A cross-national investigation". Journal of International Marketing, 16: 4-38.

Subramanian, A. M., K-H. Chai and S. Mu, 2011, "Capability reconfiguration of incumbent firms: Nintendo in the video game industry". Technovation, 31: 228-239.

Teece, D. J., 2007, "Explicating dynamic capabilities: The nature and microfoundations of (sustainable) enterprise performance". Strategic Management Journal, 28: 1319-1350.

Teece, D. J., G. Pisano and A. Shuen, 1997, "Dynamic capabilities and strategic management". Strategic Management Journal, 18: 509-533.

Thomke, S. H., 1997, "The role of flexibility in the development of new products: An empirical study". Research Policy, 26: 105-119.

Veliyath, R. and S. Shortell, 1993, "Strategic orientation, strategic planning system characteristics and performance". Journal of Management Studies, 30: 359-381.

Walker O. and R. W. Ruekert, 1987, "Marketing's role in the implementation of business strategies: A critical review and conceptual framework". Journal of Marketing, 51: 15-33.

Winter, S. G., 2003, "Understanding dynamic capabilities". Strategic Management Journal, 24: 991-995.

Wu, L.-Y., 2007, "Entrepreneurial resources, dynamic capabilities and start-up performance of Taiwan's high-tech firms". Journal of Business Research, 60: 549-555.

Wu, L.-Y., 2010, "Applicability of the resource-based and dynamic-capability views under environmental volatility". Journal of Business Research, 63: 27-31.

Yam, R. C. M., J. C. Guan, K. F. Pun and E. P. Y. Tang, 2004, "An audit of technological innovation capabilities in Chinese firms: Some empirical findings in Beijing, China". Research Policy, 33: 1123-1140.

Zahra, S., H. J. Sapienza and P. Davidsson, 2006, "Entrepreneurship and dynamic capabilities: A review, model and research agenda". Journal of Management Studies, 43: 917955 .

Zhou, K. Z. and C. B. Li, 2010, "How strategic orientations influence the building of dynamic capability in emerging economies". Journal of Business Research, 63: 224-231.

Zollo, M. and S. G. Winter, 2002, "Deliberate learning and the evolution of dynamic capabilities". Organization Science, $\mathbf{3}$ : 339-351.

Zott, C., 2003, "Dynamic capabilities and the emergence of intraindustry differential firm performance". Strategic Management Journal, 24: 97-125. 